\title{
Contralateral Vasospasm in an Uncomplicated Elective Anterior Communicating
}

\section{Artery Aneurysm Clipping}

\author{
James A. Knight II, MD, ${ }^{a}$ Mark G. Bigder, MD, MPH, ${ }^{b}$ Mauricio M. Brigido, MD, ${ }^{b}$ Yiping Li, MD, ${ }^{b}$ \\ and Gary K. Steinberg, MD, PhD \\ a Indiana University School of Medicine, Indianapolis, IN, USA \\ ${ }^{b}$ Department of Neurosurgery and Stanford Stroke Center, Stanford University School of \\ Medicine and Stanford Health Care, Stanford, CA, USA
}

\section{Email Addresses:}

James A. Knight II - jameknig@iupui.edu

Mark G. Bigder - $\underline{\text { mgbigder@stanford.edu }}$

Yiping Li - yxI129@stanford.edu

Mauricio Mandel Brigido - $\underline{\text { mmandel8@stanford.edu }}$

Gary K. Steinberg - gsteinberg@stanford.edu

\section{Corresponding Author:}

Gary K. Steinberg, MD, PhD

Department of Neurosurgery

Stanford University School of Medicine (R281)

300 Pasteur Drive

This is the author's manuscript of the article published in final edited form as: 
Stanford, CA 94305

Phone: 650-725-5562

Fax: $650-723-2815$

Email: gsteinberg@stanford.edu

Key Words:

Cerebral vasospasm; Anterior Communicating Artery Aneurysm; Clipping

\section{Short Title:}

Contralateral Vasospasm in ACoAA Clipping

\section{Previous Presentations:}

None 


\section{INTRODUCTION}

Cerebral vasospasm (CVS) is a phenomenon characterized by arterial narrowing seen on radiological imaging not attributed to atherosclerosis or catheter-induced spasm. ${ }^{1,2}$ Although CVS is frequently observed following subarachnoid hemorrhage caused by aneurysmal rupture, CVS following uncomplicated operations on unruptured aneurysms remains a rarely reported phenomenon..$^{3-7}$ Here, we present the case of a 68 -year-old male who underwent uncomplicated clipping of a right-sided anterior communicating artery aneurysm and experienced left-sided holohemispheric vasospasm five days later.

\section{CASE PRESENTATION}

This 68-year-old male with history of right facial swelling and soft tissue mass lateral to the right mandible suspicious for neoplasm underwent CT head and face which identified an incidental $5 \mathrm{~mm}$ anterior communicating artery aneurysm. The aneurysm was multilobulated, wide-based and had a Murphy's tit on the dome (Figure 1). Due to the morphology, this was not felt to be amenable to endovascular therapy and felt to be a significant rupture risk without treatment. After discussing the risks and benefits of microsurgical clipping versus conservative therapy with the patient, he decided to proceed with surgery.

The patient underwent a right pterional craniotomy for clipping of this anterior communicating artery (Acom) aneurysm without complications, without rupture of the aneurysm and with no 
blood spilled into the basal cisterns. Neuro monitoring was stable throughout the case. The surgery was uneventful, and the patient was discharged home on post-operative day (POD) 2 . However, he presented back to the ER on POD 5 with right facial droop, dysarthria, and aphasia upon waking that morning.

Postoperative CT (Figure 2) showed no evidence for subarachnoid hemorrhage or other complications. CTA (Figure 3a) demonstrates evidence of cerebral vasospasm contralateral (left) to the side of surgery while perfusion scan identified decreased perfusion in the left MCA distribution. The digital subtraction angiogram (Figure $\mathbf{4 b}$ ) showed moderate to severe vasospasm of the left middle cerebral artery, anterior cerebral artery, and posterior cerebral arteries. After administration of intra-arterial nicardipine, there was significant improvement and near-total resolution of radiographic vasospasm (Figure 4c). MRI (Figure $3 \mathbf{b}$ and $c$ ) also showed no sign of hemorrhage that would explain the spasm seen on the contralateral side of his clipping. There were small infarcts in the territory of the left MCA in the posterior insula, temporal lobe, internal capsule, corona radiata, and high left superior frontal sulcus and in the left posterior border zone.

The patient was monitored in the ICU and started on pressors. He began to improve neurologically over the next few days while speech, occupational, and physical therapies were initiated. By POD 14 he was discharged home. At the 6-month follow up the patient still reported intermittent short-term memory deficits, but had otherwise recovered to baseline in terms of facial droop and speech. 


\section{DISCUSSION}

Vasospasm following clipping of an unruptured intracranial aneurysm is uncommon, but has been previously reported in the arteries adjacent to the aneurysm., 5, 7 . Vasospasm in arteries remote and contralateral to the aneurysm site, however, has to the best of our knowledge not been documented..

The pathogenesis behind CVS remains unknown. Many studies suggest a functional vasoconstriction triggered by blood breakdown products, as well as several released chemical factors that are potential mediators of vasospasm. ${ }^{8,9}$ Investigators have suggested that erythrocytes are a necessary component of blood for the development of vasospasm in the context of subarachnoid hemorrhage. ${ }^{10}$ In vivo murine experiments have demonstrated that exposure of cerebral arterioles to hemolyzed blood or blood lysates not only causes a myogenic, vasoconstrictive response, but that increasingly prolonged exposure of arterioles to these products yields a proportionally more severe vasospastic response. ${ }^{11}$ Vasospasm in the context of elective aneurysm surgery is rare and a poorly understood entity. Various mechanisms regarding the pathophysiology underlying vasospasm following clipping of unruptured aneurysms have been proposed.

Mechanical stress applied over the arterial wall at the time of surgery has been investigated as a potential source of vasospasm, particularly when the stress is applied for long periods. ${ }^{4,5,9,12 \text {, }}$ 
${ }^{13}$ Midline shift, either via mechanical manipulation or cerebral edema, poses a possible mechanism for contralateral vasospasm. In our case, there was no midline shift and only minimal manipulation of the contralateral distal A1 segment for temporary clipping during aneurysm dissection and clipping. Therefore, these mechanisms were likely not a factor in this specific case.

Manipulation of cerebral arteries already irritated by subarachnoid blood may yield a vasospasm that is not detectable on angiography but still has a clinically significant impact: surgery-induced vasospasm may facilitate further decrease of cerebral blood flow (CBF) by the hemorrhage itself, with retraction on swollen brain further contributing to $\mathrm{CBF}$ impairment. ${ }^{13-17}$ CBF studies, supported by SPECT imaging, indicate that CBF is significantly lowered on the side that has been surgically treated. ${ }^{15,18,19}$ Kitazawa and colleagues analyzed their series of 30 patients undergoing elective clipping of a paraclinoid aneurysm and found that nine patients had radiographic vasospasm postoperatively, three of which were symptomatic and required treatment. They demonstrated that number of clips used and use of temporary occlusion were statistically significant factors associated with vasospasm in their series of elective patients and concluded that the combination of mechanical stimulation to the vascular wall and spilled blood at the operative site were responsible for the cases of observed vasospasm. Despite these observations, the latency period for vasospasm in unruptured aneurysms has been reported to occur between POD 1 and POD 28, suggesting that factors other than mechanical stress may be involved. ${ }^{4}$ 
Work by Peerless and colleagues suggests a mechanism that could explain the contralateral vasospasm witnessed in our patient. They indicated that vessels remote from direct contact with blood exhibited reactive narrowing one week after $\mathrm{SAH} .{ }^{20}$ This suggested that vasospasm could be mediated by a central control mechanism acting through the sympathetic nervous system. ${ }^{10,20}$ The possibility that the trigemino-cerebrovascular system (TCVS) may be the centralized mechanism in question provides a potential avenue of investigation.

The activities of the TCVS, part of a complex nerve plexus surrounding the arteries of the circle of Willis, suggest another mechanism. ${ }^{4,9,21,22}$ The axons of the TCVS reach the basal arteries via the ophthalmic and maxillary divisions of the trigeminal nerve and may contribute to headache development. They also appear to be involved in maintaining normal vessel diameter by constantly releasing vasodilatatory peptides such as substance $\mathrm{P}$ and calcitonin gene-related peptide (CGRP). ${ }^{22}$ It is hypothesized that TCVS activation and subsequent peptide depletion is due not only to chemical factors, but also mechanical distortion of the arterial wall from retraction or aneurysm clipping. ${ }^{4,9}$

Another proposed theory is the "hypothalamic" theory which posits that mechanical or vascular compromise of the hypothalamus can promote the release of vasospastic mediators. Although the hypothalamic theory fails to explain the frequent association between vasospasm and more peripheral aneurysms, it remains a possible factor for operations involving midline structures, such as the Acom. ${ }^{7,9,23,24}$ 
It remains difficult to explain the etiology of the contralateral vasospasm in our patient given the uncomplicated presentation and surgery. A combination of the above factors may have played a role, and cannot be ruled out. It must be acknowledged that there is always spilled blood during the opening of a craniotomy, and although the quantity is small, some patients could have a "hypersensitivity" to blood degradation products.

This rare case emphasizes the roles that aneurysm location, vasoconstrictive agents, and nerve plexuses may play in triggering vasospasm, and the possibility that involvement of some of these factors can yield more unusual clinical presentations. This report also serves to demonstrate the importance of remaining vigilant about monitoring and investigating for signs of vasospasm in patients undergoing elective aneurysm surgery.

\section{ACKNOWLEDGEMENTS}

We thank Christine Plant for editorial assistance with the manuscript. 


\section{REFERENCES}

1. Frontera JA, Fernandez A, Schmidt JM, et al. Defining vasospasm after subarachnoid hemorrhage: what is the most clinically relevant definition? Stroke. 2009;40(6): 1963-1968. https://doi.org/10.1161/strokeaha.108.544700.

2. Kassell NF, Torner JC, Haley EC, Jr., Jane JA, Adams HP, Kongable GL. The International Cooperative Study on the Timing of Aneurysm Surgery. Part 1: Overall management results. Journal of neurosurgery. 1990;73(1): 18-36. https://doi.org/10.3171/jns.1990.73.1.0018.

3. Bloomfield SM, Sonntag VK. Delayed cerebral vasospasm after uncomplicated operation on an unruptured aneurysm: case report. Neurosurgery. 1985;17(5): 792-796. https://doi.org/10.1227/00006123-198511000-00011.

4. Hashimoto H, Kameda M, Yasuhara T, Date I. A Case of Unexpected Symptomatic Vasospasm after Clipping Surgery for an Unruptured Intracranial Aneurysm. Journal of stroke and cerebrovascular diseases : the official journal of National Stroke Association. 2016;25(3): e25-27. https://doi.org/10.1016/j.jstrokecerebrovasdis.2015.11.029.

5. Kitazawa K, Hongo K, Tanaka Y, Oikawa S, Kyoshima K, Kobayashi S. Postoperative vasospasm of unruptured paraclinoid carotid aneurysms: analysis of 30 cases. Journal of clinical neuroscience : official journal of the Neurosurgical Society of Australasia. 2005;12(2): 150-155. https://doi.org/10.1016/j.jocn.2004.02.023.

6. Tsyben A, Paldor I, Laidlaw J. Cerebral vasospasm and delayed ischaemic deficit following elective aneurysm clipping. Journal of clinical neuroscience : official journal of the Neurosurgical Society of Australasia. 2016;34: 33-38.

https://doi.org/10.1016/j.jocn.2016.06.006. 
7. Yang K, Ahn JS, Park JC, Kwon DH, Kwun BD. Clinical and Angiographical Delayed Cerebral Vasospasms After Uncomplicated Surgical Clipping of Unruptured Intracranial Aneurysms: Illustrated Review and Two Case Reports. Turkish neurosurgery. 2015;25(4): 662665. https://doi.org/10.5137/1019-5149.Jtn.9912-13.1.

8. Findlay JM. Cerebral Vasospasm. In: Winn HR, ed. Youmans Neurological Surgery. 5th ed. Philadelphia, PA: Saunders (Elsevier); 2004:1839-1864.

9. Paolini S, Kanaan Y, Wagenbach A, Fraser K, Lanzino G. Cerebral vasospasm in patients with unruptured intracranial aneurysms. Acta neurochirurgica. 2005;147(11): 1181-1188; discussion 1188. https://doi.org/10.1007/s00701-005-0613-4.

10. Nomura Y, Kawaguchi M, Yoshitani K, et al. Retrospective analysis of predictors of cerebral vasospasm after ruptured cerebral aneurysm surgery: influence of the location of subarachnoid blood. J Anesth. 2010;24(1): 1-6. https://doi.org/10.1007/s00540-009-0836-2.

11. Deng W, Kandhi S, Zhang B, Huang A, Koller A, Sun D. Extravascular Blood Augments Myogenic Constriction of Cerebral Arterioles: Implications for Hemorrhage-Induced Vasospasm. J Am Heart Assoc. 2018;7(8). https://doi.org/10.1161/JAHA.118.008623.

12. Findlay JM, Macdonald RL, Weir BK, Grace MG. Surgical manipulation of primate cerebral arteries in established vasospasm. Journal of neurosurgery. 1991;75(3): 425-432. https://doi.org/10.3171/jns.1991.75.3.0425.

13. Hosoda K, Fujita S, Kawaguchi T, Shose Y, Hamano S, Iwakura M. Effect of clot removal and surgical manipulation on regional cerebral blood flow and delayed vasospasm in early aneurysm surgery for subarachnoid hemorrhage. Surgical neurology. 1999;51(1): 81-88. https://doi.org/10.1016/s0090-3019(97)00508-9. 
14. Macdonald RL, Wallace MC, Coyne TJ. The effect of surgery on the severity of vasospasm. Journal of neurosurgery. 1994;80(3): 433-439. https://doi.org/10.3171/jns.1994.80.3.0433.

15. Wachter D, Kreitschmann-Andermahr I, Gilsbach JM, Rohde V. Early surgery of multiple versus single aneurysms after subarachnoid hemorrhage: an increased risk for cerebral vasospasm? Journal of neurosurgery. 2011;114(4): 935-941. https://doi.org/10.3171/2010.10.JNS10186.

16. Westermaier T, Jauss A, Eriskat J, Kunze E, Roosen K. Acute vasoconstriction: decrease and recovery of cerebral blood flow after various intensities of experimental subarachnoid hemorrhage in rats. Journal of neurosurgery. 2009;110(5): 996-1002. https://doi.org/10.3171/2008.8.JNS08591.

17. Yoshimoto $\mathrm{Y}$, Wakai S, Satoh A, Tejima T, Hamano M. A prospective study on the effects of early surgery on vasospasm after subarachnoid hemorrhage. Surgical neurology. 1999;51(4): 392-397; discussion 397-398. https://doi.org/10.1016/s0090-3019(98)00124-4.

18. Mickey B, Vorstrup S, Voldby B, Lindewald H, Harmsen A, Lassen NA. Serial measurement of regional cerebral blood flow in patients with SAH using 133Xe inhalation and emission computerized tomography. Journal of neurosurgery. 1984;60(5): 916-922. https://doi.org/10.3171/jns.1984.60.5.0916.

19. Rosen JM, Butala AV, Oropello JM, et al. Postoperative changes on brain SPECT imaging after aneurysmal subarachnoid hemorrhage. A potential pitfall in the evaluation of vasospasm. Clin Nucl Med. 1994;19(7): 595-597. https://doi.org/10.1097/00003072-199407000-00006. 
20. Peerless SJ, Fox AJ, Komatsu K, Hunter IG. Angiographic study of vasospasm following subarachnoid hemorrhage in monkeys. Stroke. 1982;13(4): 473-479. https://doi.org/10.1161/01.str.13.4.473.

21. Buki A, Horvath Z, Kallo I, Liposits Z, Lengvari I, Doczi TP. Peptidergic innervation of human cerebral blood vessels and saccular aneurysms. Acta neuropathologica. 1999;98(4): 383388. https://doi.org/10.1007/s004010051098.

22. Edvinsson L, Juul R, Jansen I. Perivascular neuropeptides (NPY, VIP, CGRP and SP) in human brain vessels after subarachnoid haemorrhage. Acta neurologica Scandinavica. 1994;90(5): 324-330. https://doi.org/10.1111/j.1600-0404.1994.tb02732.x.

23. Wilkins RH. Hypothalamic dysfunction and intracranial arterial spasms. Surgical neurology. 1975;4(5): 472-480.

24. Wilson JL, Feild JR. The production of intracranial vascular spasm by hypothalamic extract. Journal of neurosurgery. 1974;40(4): 473-479.

https://doi.org/10.3171/jns.1974.40.4.0473. 


\section{FIGURE LEGENDS}

Figure 1. A) CT angiogram demonstrating broad-based, $5 \mathrm{~mm}$, multi-lobulated aneurysm (arrow), incorporating both A2 origins into its base. B) A Murphy's tit was present on one of the aneurysm lobes.

Figure 2. Head CT (post-op day 5) without contrast demonstrating expected post-surgical changes related to interval right frontotemporal craniotomy and clipping of anterior communicating artery (Acom) aneurysm (arrow) without any evidence of significant subarachnoid hemorrhage, hydrocephalus or post-operative complications.

Figure 3. a) CT angiogram demonstrating moderate to severe vasospasm of the left middle cerebral artery, anterior cerebral artery and posterior cerebral arteries. $\mathbf{b}$ and c) MRI Brain with DWI shows small infarcts in the territory of the left MCA in the posterior insula, temporal lobe, internal capsule, corona radiata, high left superior frontal sulcus, and posterior border zone.

Figure 4. Cerebral angiogram, AP view of the (a) right internal carotid artery and its terminal branches with normal caliber of vessels. (b) Cerebral angiogram demonstrating moderate to severe vasospasm of the left middle cerebral, anterior cerebral and posterior cerebral arteries. (c) After administration of intra-arterial nicardipine, there was significant improvement and near-total resolution of vasospasm.

\section{SOURCE OF FUNDING}


This research did not receive any specific grant from funding agencies in the public, commercial, or not-for-profit sectors.

\section{CONFLICTS OF INTEREST}

Dr. Steinberg is a consultant for Qool Therapeutics, Peter Lazic US, NeuroSave, SanBio and Zeiss. The other co-authors of this manuscript have no conflicts of interest in the subject under discussion. 


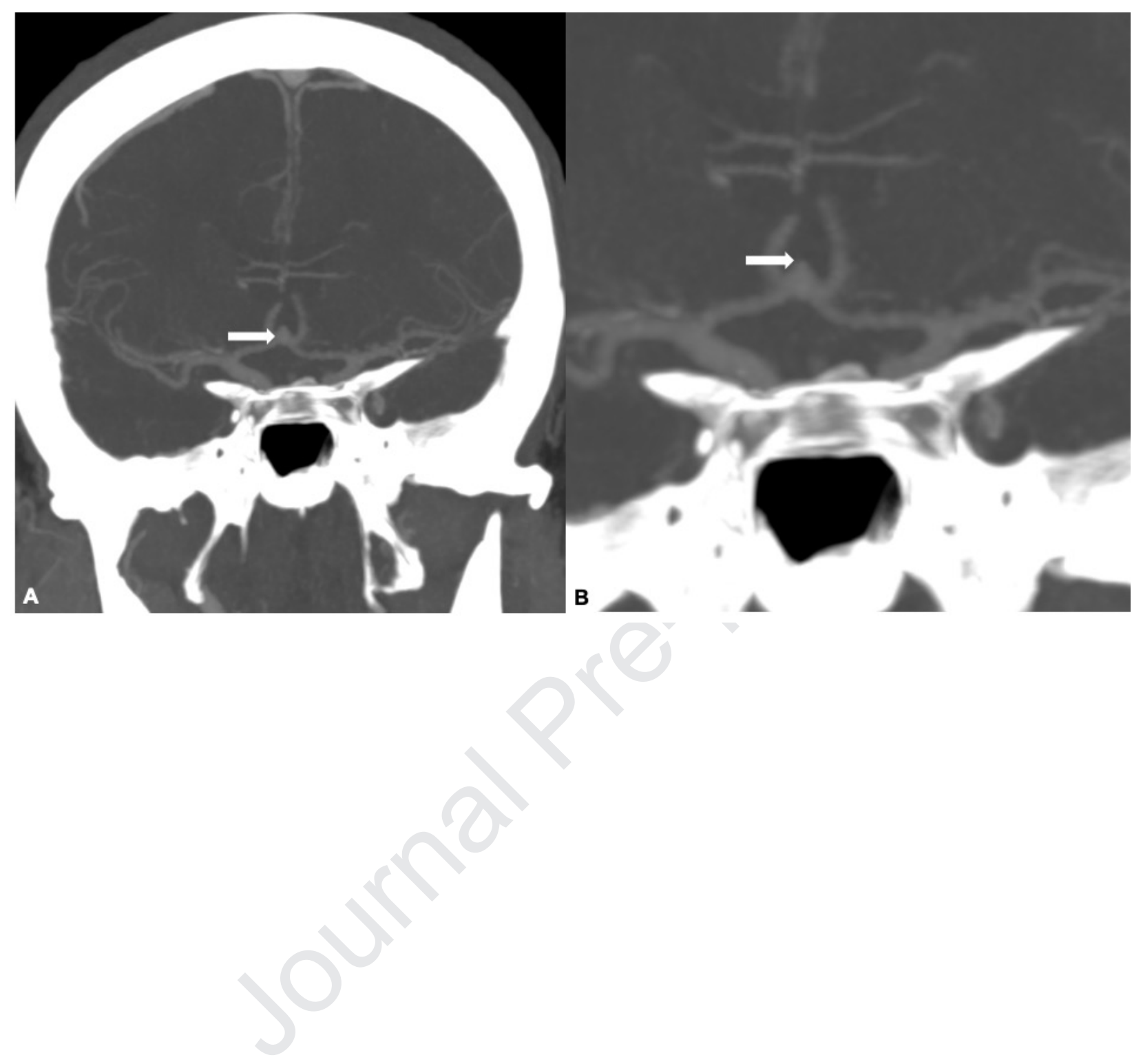




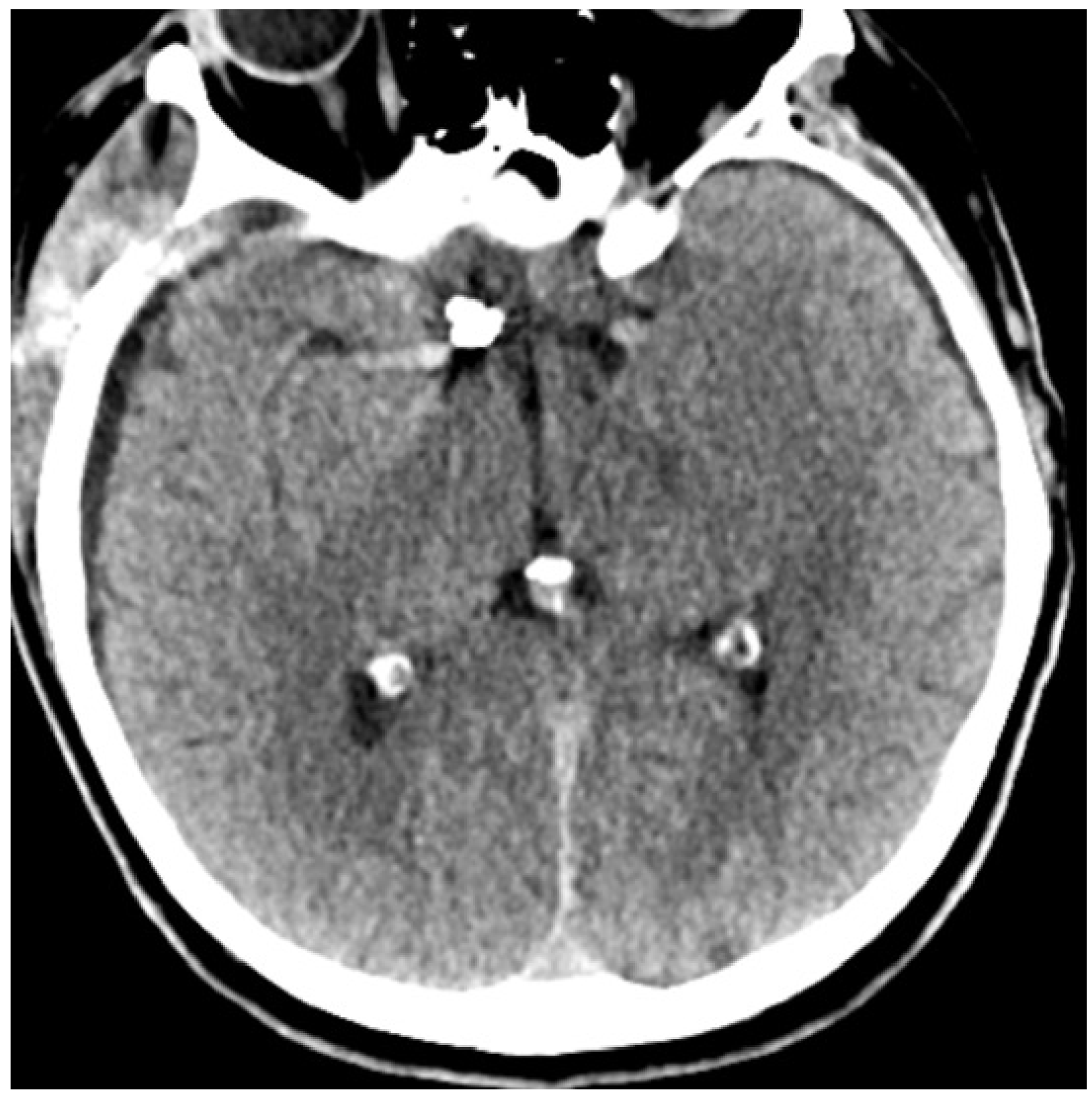




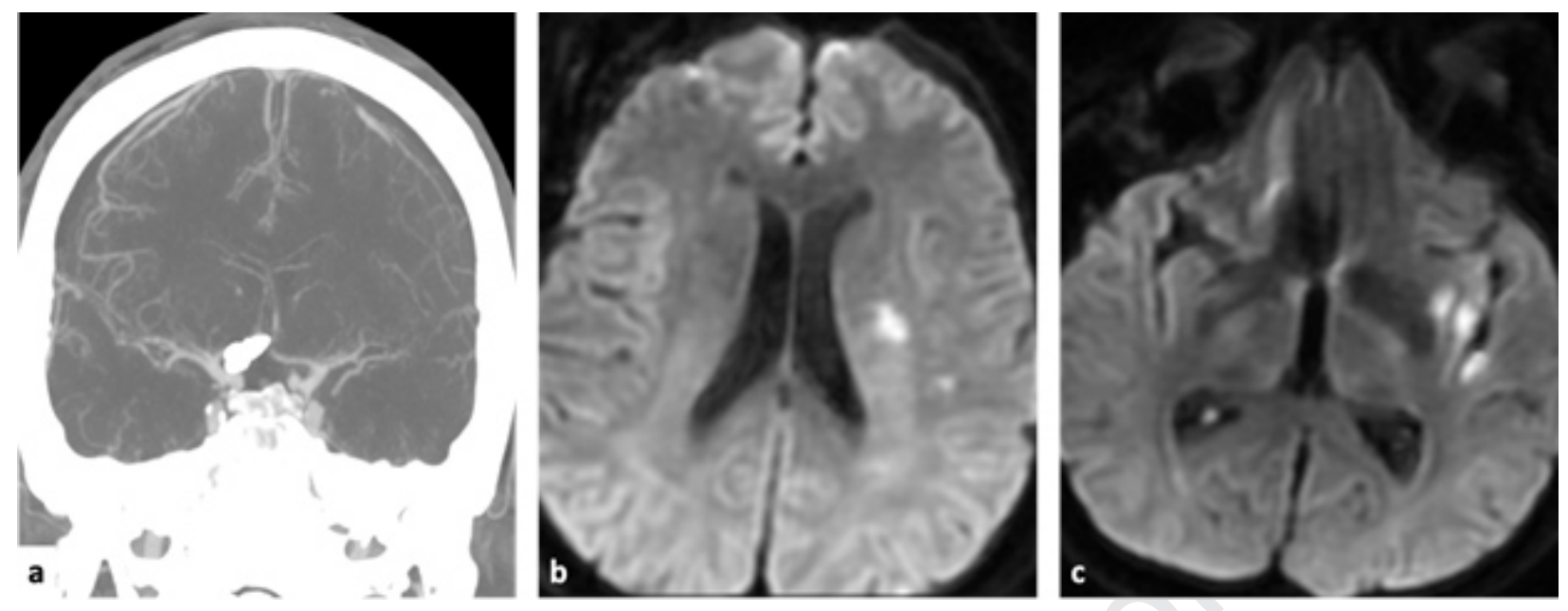



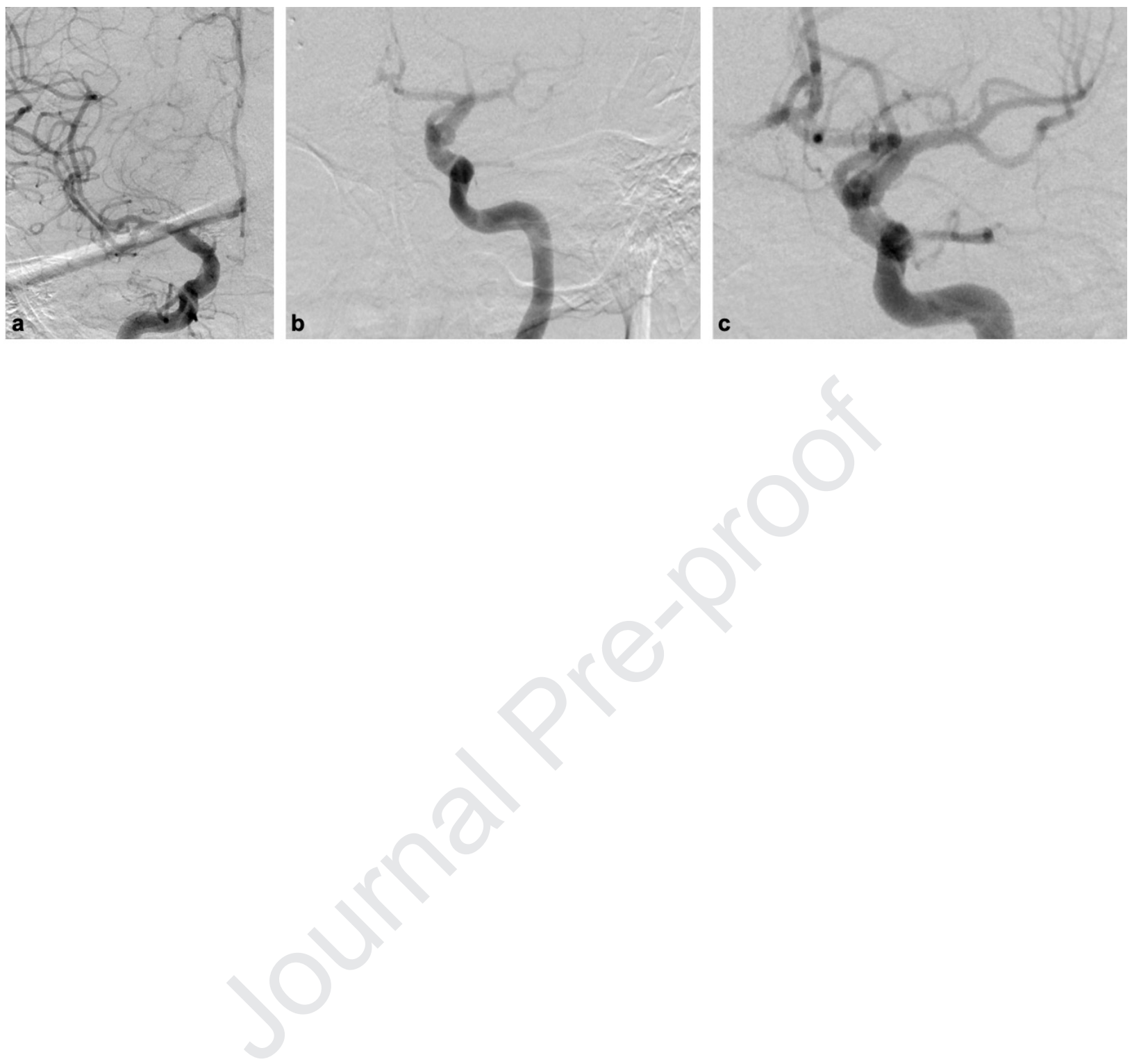
Contralateral Vasospasm in an Uncomplicated Elective Anterior Communicating Artery Aneurysm Clipping

Highlights:

1. A cerebral vasospasm (CVS) following clipping of an unruptured aneurysm is rare

2. Aneurysm location, vasodilatatory agents, and nerve plexuses may trigger vasospasm

3. Blood degradation products may cause vasospasm in "hypersensitive" patients 
Contralateral Vasospasm in an Uncomplicated Elective Anterior Communicating Artery Aneurysm Clipping

Abbreviations:

Cerebral vasospasm (CVS)

Anterior communicating artery (Acom)

Post-operative day (POD)

Trigemino-cerebrovascular system (TCVS)

Calcitonin gene-related peptide (CGRP)

Cerebral blood flow (CBF) 